\title{
Properties of Electrospun $\mathrm{TiO}_{2}$ Nanofibers
}

\author{
Bianca Caratão, ${ }^{1}$ Edgar Carneiro, ${ }^{1}$ Pedro Sá, ${ }^{2}$ Bernardo Almeida, ${ }^{2}$ and Sandra Carvalho ${ }^{1,3}$ \\ ${ }^{1}$ GRF-CFUM, University of Minho, Campus of Azurém, 4800-058 Guimarães, Portugal \\ ${ }^{2}$ CFUM, University of Minho, Campus of Gualtar, 4700-057 Braga, Portugal \\ ${ }^{3}$ SEG-CEMUC Mechanical Engineering Department, University of Coimbra, 3030-788 Coimbra, Portugal
}

Correspondence should be addressed to Bianca Caratão; bianca.caratao@gmail.com

Received 6 February 2014; Accepted 19 May 2014; Published 3 June 2014

Academic Editor: Valery Khabashesku

Copyright (C) 2014 Bianca Caratão et al. This is an open access article distributed under the Creative Commons Attribution License, which permits unrestricted use, distribution, and reproduction in any medium, provided the original work is properly cited.

\begin{abstract}
Titanium oxide filled polyvinylpyrrolidone (PVP) composite nanofibers have been prepared via a simple electrospinning technique. The combination of good $\mathrm{TiO}_{2}$ properties with its high surface area leads these nanofibers into having a vast applicability such as cosmetics, scaffolds for tissue engineering, catalytic devices, sensors, solar cells, and optoelectronic devices. The structural and chemical properties of the prepared samples have been studied. The presence of the $\mathrm{TiO}_{2}$ phase on the nanofibers was confirmed. An anatase to rutile transformation was observed at $600^{\circ} \mathrm{C}$. Regarding the thermogravimetric and differential thermal analysis (TGA/DTA), the TIP decomposition and the PVP evaporation at $225^{\circ} \mathrm{C}$ were verified.
\end{abstract}

\section{Introduction}

Electrospinning is a simple and versatile technique that is capable of producing nanofibers with diameters ranging from 50 to $500 \mathrm{~nm}$ [1]. This nanofiber preparation method has the advantages of easy deposition and versatile in the manufacture of polymeric materials, composites, and ceramics. The interest of this technique for producing ceramic nanofibers has grown exponentially since 2002 [1].

The electrospinning process involves a high voltage source connected to a needle and a metallic collector where the fibers are deposited [2]. The needle is attached to injection pump, where is the polymer solution or melt, and consists of the positive electrode. The collector is connected to the negative electrode, thus creating a potential difference. In this way the electric field created, stretches the drop that forms on the needle tip, which is then deformed into a conical shape (Taylor cone) [3]. When the applied electric field exceeds the surface tension of the drop, the solution is ejected in the form of an electrically charged jet, reaching the negative electrode which is the collector [4]. During this process, the solvent is evaporated resulting in the deposition of nanofibers over the collector. The diameter of the fibers can be adjusted by varying the rheological properties of the solution and turning the processing parameters $[1,5,6]$.
The importance and applicability of nanofibers have been a common theme in the field of nanotechnology. These materials, due to their nanosize, enjoy a range of attractive properties compared to known materials, such as high ratio area/volume, flexibility of structures, and mechanical performance (stiffness and tensile strength) [5].

Titanium dioxide $\left(\mathrm{TiO}_{2}\right)$ or titania can be found in three different crystalline forms: anatase, rutile, and brookite. However, the rutile phase is thermodynamically more stable. $\mathrm{TiO}_{2}$ is a semiconductor with interesting properties, such as transparency to visible light, a high refraction index, and a low absorption coefficient [6].

The formation of the nanofibers with $\mathrm{TiO}_{2}$ is the only form of combining their elevated surface area and the $\mathrm{TiO}_{2}$ intrinsic semiconductor properties, thereby opening an enormous potential of this material, for applications. The anatase is a more photoactive phase due to its low velocity recombination of photogenerated charges in its structure, thus, this $\mathrm{TiO}_{2}$ phase has a vast applicability such as sensors, solar cells [7], optoelectronic devices, and catalytic devices $[6,8]$ that have an important role in disinfection applications or air and water cleaning [6]. The rutile phase, due to their low intrinsic photocatalytic activity, can be used in cosmetic field [9]. The nanofibers of rutile phase can also be applied in the medical area as scaffolds for tissue engineering $[10,11]$. 
TABLE 1: Variations and different amounts of precursor and polymeric matrix.

\begin{tabular}{lcc}
\hline Solutions & TIP + acetic acid & PVP + ethanol \\
\hline A & $1,5 \mathrm{~mL}+3 \mathrm{~mL}$ & $0,45 \mathrm{~g}+10 \mathrm{~mL}$ \\
B & $0,75 \mathrm{~mL}+1,5 \mathrm{~mL}$ & $0,45 \mathrm{~g}+10 \mathrm{~mL}$ \\
C & $1,5 \mathrm{~mL}+3 \mathrm{~mL}$ & $0,5 \mathrm{~g}+5 \mathrm{~mL}$ \\
\hline
\end{tabular}

This study aims at producing titanium dioxide nanofibers to combine the advantages of this material with the simplicity and versatility of the electrospinning technique. Furthermore, it has the objective of studying the behavior of the $\mathrm{TiO}_{2}$ nanofibers at elevated temperatures. This study is different from the known articles due to high temperatures. The main aim of this research is to study the influence of the concentration of the $\mathrm{Ti}(\mathrm{IV})$-isopropoxide (TIP) in the production of $\mathrm{TiO}_{2}$ nanofibers. And the second aim of this study is to understand what happens to the $\mathrm{TiO}_{2}$ at different temperatures for optimizing functionality depending on the required application.

\section{Materials and Methods}

The solution comprises Ti(IV)-isopropoxide precursor, which is subsequently added to a solvent and acetic acid. For a better control of the rheological properties of the solution, it will be added to a polymer matrix, of polyvinylpyrrolidone (PVP), forming a solution. This matrix was chosen due to its high molecular weight $1300000 \mathrm{~g} / \mathrm{mol}$, which ensures that even at low concentrations the solution presents pairing of chains, enough for its stretching through the action of the electric field $[6,12]$. The polymer is solved in ethanol, which evaporates during deposition, along with the other solvents involved. This leaves a dry PVP/TIP set of nanofibers in the collector.

In order to determine the optimal solution for the production of titanium dioxide nanofibers, three solutions were prepared (Table 1). The production of A and B solutions was produced with the same quantity of polymeric matrix (PVP); however, the precursor (TIP) was reduced to half the quantity in order to find out if it was possible to reduce the cost of the solution without altering its efficiency. Knowing that the concentration of PVP in ethanol can be increased to $0.1 \mathrm{~g} / \mathrm{mL}$ [13], solution $\mathrm{C}$ was made, with the same quantity of precursor as in solution A.

Each solution was mixed with the aid of a magnetic stirrer at room temperature until a homogeneous solution is reached.

The solutions were then inserted into the injection pump, containing a needle (stainless steel $0.5 \mathrm{~mm}$ in diameter) and a vertically attached electrospinning device. The needle was connected to a high voltage and the solution was deposited at a rate of 0.1 to $0.5 \mathrm{~mm} / \mathrm{h}$. A fan-shaped foil was used as a collector for better visualization of the nanofibers produced. The needle collector distance was $12 \mathrm{~cm}$. The electric field created between the needle and the collector was $8 \mathrm{kV}$. The samples were deposited for 10 minutes at room temperature.
TABLE 2: Quantitative and qualitative analysis obtained by EDS.

\begin{tabular}{lcccc}
\hline Element & \multicolumn{2}{c}{ TiK } & \multicolumn{2}{c}{ OK } \\
nanofibers of solution & Wt\% & At\% & Wt\% & At\% \\
\hline A & 67,78 & 41,27 & 32,22 & 58,73 \\
B & 66,26 & 39,61 & 33,74 & 60,39 \\
C & 71,79 & 45,94 & 28,21 & 54,06 \\
\hline
\end{tabular}

The nanofibers were calcinated at maximum temperature of $1400^{\circ} \mathrm{C}$, in a Wire Wound Tube Furnace. To reach the calcination temperature a heating rate of $5^{\circ} \mathrm{C} / \mathrm{min}$ was used. The isothermal plateau was maintained for 60 minutes and subsequent cooling was at the natural rate.

\section{Results and Discussion}

3.1. The Effect of the Different Solutions Concentration. An EDS analysis of the nanofibers obtained each solution was carried out and showed the presence of $\mathrm{TiO}_{2}$ (Table 2).

The scanning electron microscopy (SEM) analyses for the different solutions before and after calcination at $1200^{\circ} \mathrm{C}$ are shown in Figure 1. Calcination was carried out at this temperature with the objective of discovering if the nanofiber structure changes with the increase in temperature. Figure 1 illustrates a decrease in the nanofibers size from solution A to solution B after annealing. This behavior is explained by the decrease of the TIP precursor. The increase of the average diameter of the nanofiber mat from $\mathrm{A}$ to $\mathrm{C}$ is due to the higher concentration of polymer increasing the viscosity of the solution that leads to increased loads which initiate the fiber formation that may not be sufficient to stretch the solution to the fiber diameters as thin as desired (from 200 to $400 \mathrm{~nm}$ ); these dimensions required for the nanofibers have good properties, such as high ratio area/volume, flexibility of structures, and mechanical performance [14].

Changes in morphology before and after calcination are related with drastic change in the crystal structure [15-17]. One can also see that after annealing there is a reduction in the size of nanofibers, due to the PVP polymer evaporation and the $\mathrm{TiO}_{2}$ crystallization [15].

Analyzing the nanofibers after annealing corresponding to precursor solutions of different concentrations, it was found that the sample corresponding to solution $\mathrm{C}$ contains nanofibers with $888 \mathrm{~nm}$ average diameter. This diameter is not within the envisaged interval from 200 to $400 \mathrm{~nm}$. The fiber mat from solution A contains more defects than one formed from solution B. As such, it was concluded that the nanofibers corresponding to solution $\mathrm{B}$ were chosen for the subsequent analysis and tests. Through the analysis in Figure 1, it can be verified that with the increase in temperature the nanofiber structure does not alter; however, it causes an increase in $\mathrm{TiO}_{2}$ crystals.

3.2. Effect of Temperature on $\mathrm{TiO}_{2}$ Nanofibers. The nanofibers produced with solution $\mathrm{B}$ were calcined at different temperatures. Figure 2 represents the X-ray diffraction (XRD) spectra for the sample with different annealing temperatures. 


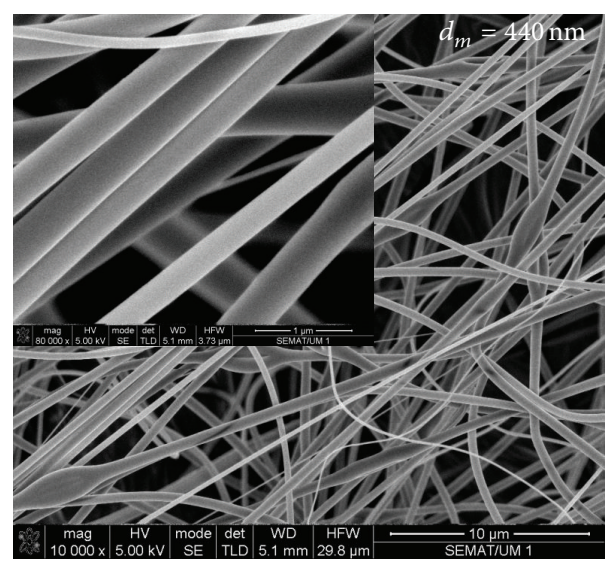

(1)

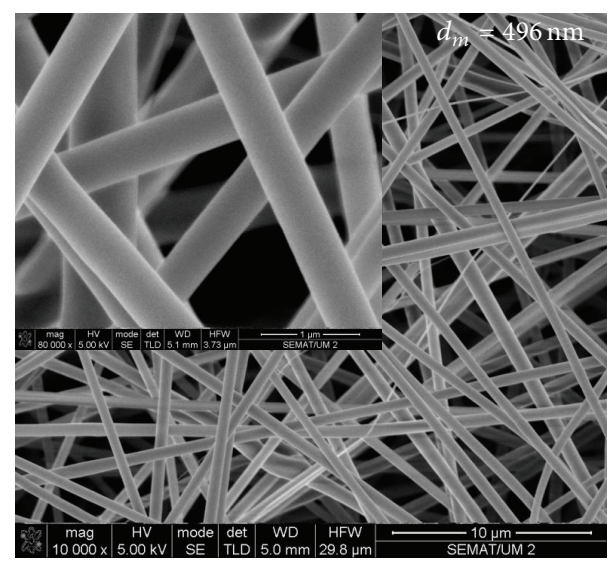

(1)

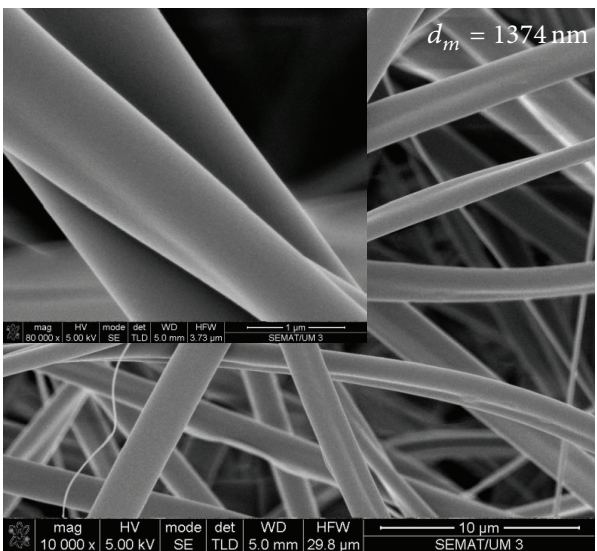

(1)
(A)

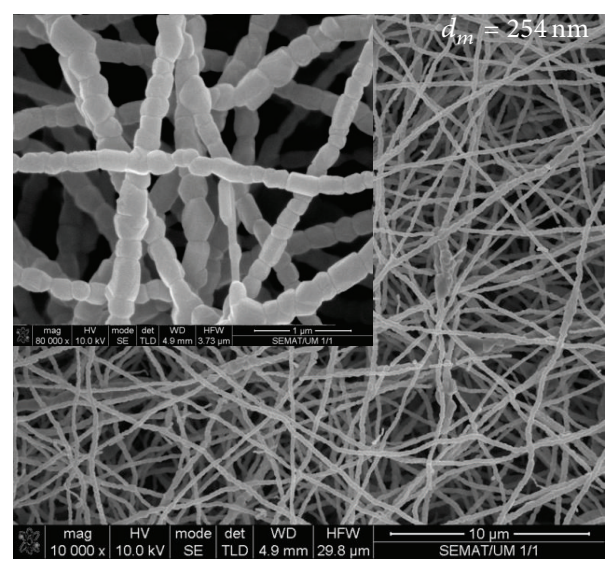

(2)

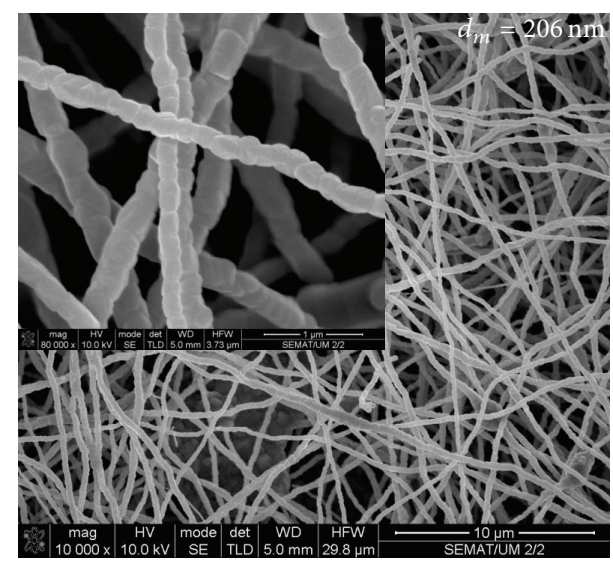

(2)

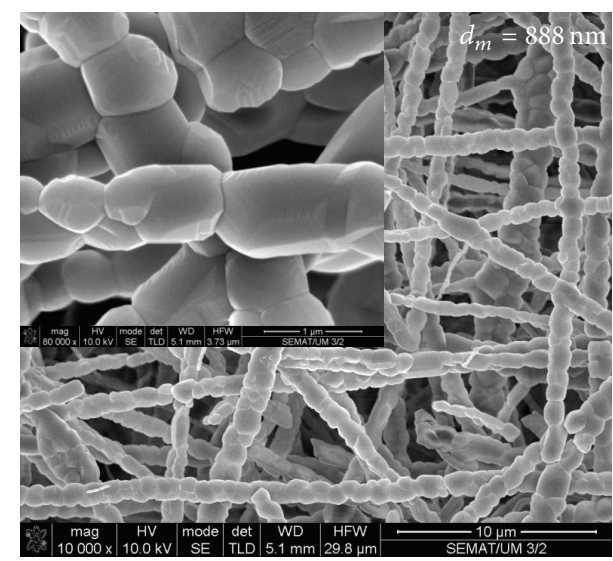

(2)

(C)

FIGURE 1: SEM analysis of solutions (A), (B), and (C) before (1) and after calcining (2).

Also are the peak positions (vertical lines) corresponding to the anatase (ICDD 00-021-1272) and rutile (ICDD 00-0211276) phases expected for $\mathrm{TiO}_{2}$.

According to the XRD results (Figure 2) it appears that nanofibers calcinated at $400^{\circ} \mathrm{C}$, temperature at which anatase crystals begin to form, have a nanocrystalline structure. At $600^{\circ} \mathrm{C}$ rutile starts to become more evident. However, the predominant phase is still anatase. With increasing temperature the rutile phase grows so that at $800^{\circ} \mathrm{C}$ it becomes the one that has a higher percentage in the samples, as expected $[12,15,18]$.

With increasing temperature the grain size also increases; this increase in the grain size is due to the sudden increase of temperature. The grain size shown in Table 3 was determined by the Scherrer equation.

The increase in grain size causes an increase in its thickness, thus, the atoms' levels of energy will increase resulting in the reduction of its bandgap. Besides the bandgap, 
TABLE 3: Grain size and phase with changes of temperature.

\begin{tabular}{lccc}
\hline Temperature $\left({ }^{\circ} \mathrm{C}\right)$ & Crystallographic plane & Phase & Grain size $(\mathrm{nm})$ \\
\hline 400 & $(011)$ & Amorphous & 5.0 \\
\hline 500 & $(011)$ & Anatase & 8.4 \\
600 & $(011)$ & & 15.7 \\
\hline 700 & $(110)$ & & 38.4 \\
800 & $(110)$ & Rutile & 48.1 \\
1000 & $(110)$ & & 64.2 \\
1200 & $(110)$ & & 71.0 \\
1400 & $(110)$ & 613.0 \\
\hline
\end{tabular}

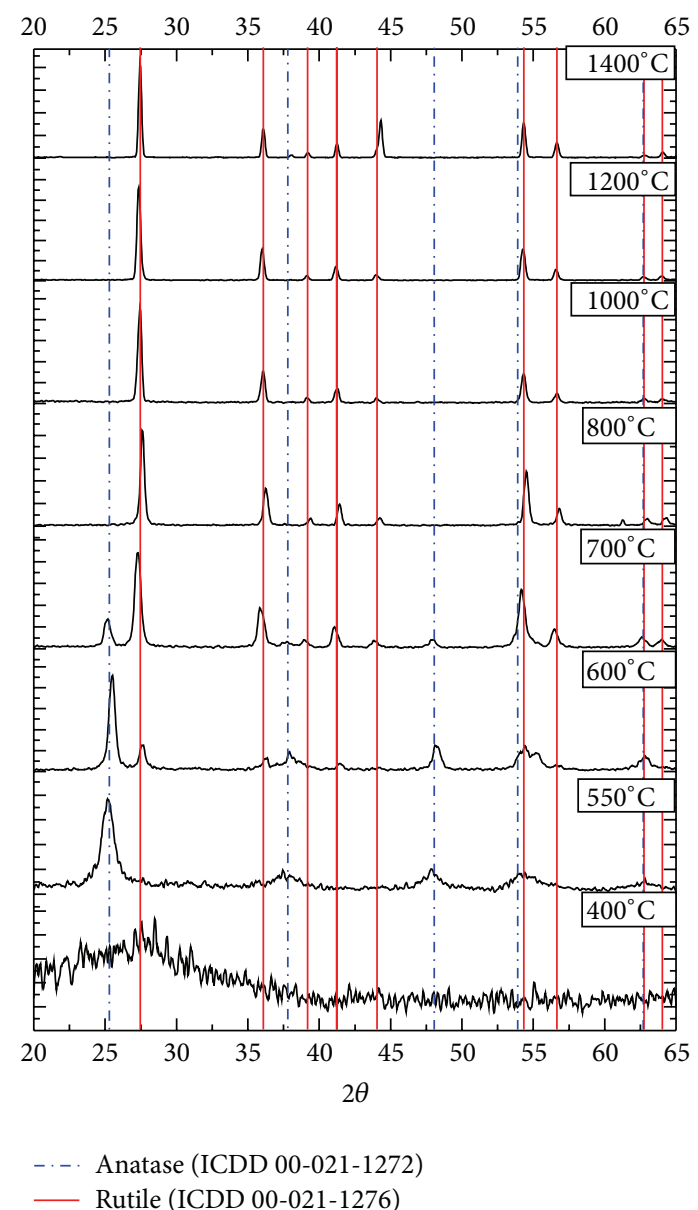

FIgURE 2: Graph representing the XRD of solution $\mathrm{B} \mathrm{TiO}_{2}$ nanofibers.

the grain size will affect the area's surface; for a constant volume, the bigger the particle is, the less its surface area will be [19]. For anatase phase, the $\mathrm{TiO}_{2}$ photovoltaic efficiency is improved with the decrease of the grain size; this is due to the increase in the photons absorption and improved interfacial characteristics [20]. For rutile phase with the decrease of grain size, their ability to dispersion visible light is reduced; however they maintain a high UV-scattering ability [21].

The differential thermal analysis (DTA) curve of heat flow, shown in Figure 3, indicates two transformations with

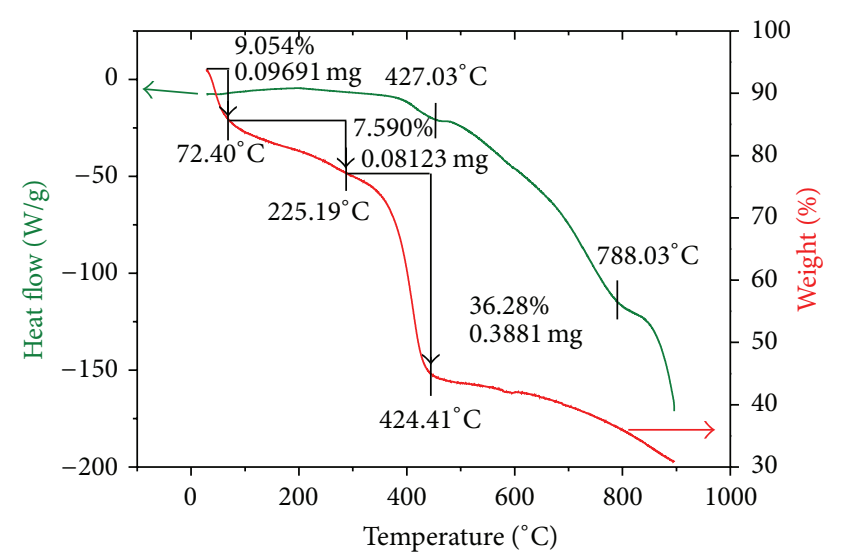

FIgURE 3: Graph representing $\mathrm{TiO}_{2}$ nanofibers' DTA and TGA of solution $\mathrm{B}$.

increasing temperature. The first exothermic peak at $450.03^{\circ} \mathrm{C}$ corresponds to the anatase phase of $\mathrm{TiO}_{2}$ while the second exothermic peak occurs at $788.03^{\circ} \mathrm{C}$ and corresponds to the transformation of the rutile phase. These results are in accordance with the X-ray diffraction and the literature [15, 22, 23].

From the obtained TGA curves (Figure 3), the existence of three losses was verified. The first loss occurs at $72.40^{\circ} \mathrm{C}$ and is related to moisture and solvent loss (ethanol and acetic acid). The loss at $225.19^{\circ} \mathrm{C}$ is due to TIP decomposition in conjunction with the degradation of PVP dehydration through a polymer side chain. The loss at $424.41^{\circ} \mathrm{C}$ occurs due to the formation of anatase crystals. These transformations are in agreement with the literature $[15,22,23]$.

\section{Conclusion}

$\mathrm{TiO}_{2}$ nanofibers with average diameter of $206 \mathrm{~mm}$ were successfully produced through the electrospinning technique. It was found that the best $\mathrm{TiO}_{2}$ nanofibers are obtained from solution $\mathrm{B}$ that contains $0.75 \mathrm{~mL}$ TIP (in $1.5 \mathrm{~mL}$ acetic acid) and $0.45 \mathrm{~g}$ PVP (in $10 \mathrm{~mL}$ ethanol). The scanning electron microscope allowed for the nanofibers absorption before and after calcination; this proved that its structure is maintained with the increase in temperature, all that occurs is the increase in $\mathrm{TiO}_{2}$ crystal size. The structural 
transformation from anatase to rutile occurs in the range $600^{\circ} \mathrm{C}$ and $800^{\circ} \mathrm{C}$. These results were confirmed through DSC studies. For applications that require an anatase phase, the $\mathrm{TiO}_{2}$ will have to be annealed at a temperature equal or lower than $600^{\circ} \mathrm{C}$. Regarding the TGA study, the TIP decomposition and PVP evaporation through dehydration in the polymer lateral chain were verified at $225^{\circ} \mathrm{C}$.

\section{Conflict of Interests}

The authors declare that they have no conflict of interests regarding to the publication of this paper.

\section{Acknowledgments}

This research is sponsored by FEDER funds through the program COMPETE - "Programa Operacional Factores de Competitividade" - and by national funds through FCT"Fundação para a Ciência e a Tecnologia" - in the framework of the Strategic Projects PEST-C/FIS/UI607/2011 and the project Matepro-Optimizing Materials and Processes, ref. NORTE-07-0124-FEDER-000037, and it is also cofunded by the "Programa Operacional Regional do Norte" (ON.2-O Novo Norte), under the "Quadro de Referência Estratégico Nacional" (QREN), through the "Fundo Europeu de Desenvolvimento 8 Regional” (FEDER).

\section{References}

[1] I. S. Chronakis, "Novel nanocomposites and nanoceramics based on polymer nanofibers using electrospinning process-a review," Journal of Materials Processing Technology, vol. 167, no. 2-3, pp. 283-293, 2005.

[2] W. E. Teo and S. Ramakrishna, "A review on electrospinning design and nanofibre assemblies," Nanotechnology, vol. 17, no. 14, pp. R89-R106, 2006.

[3] P. K. Panda and S. Ramakrishna, "Electrospinning of alumina nanofibers using different precursors," Journal of Materials Science, vol. 42, no. 6, pp. 2189-2193, 2007.

[4] N. M. Thoppey, J. R. Bochinski, L. I. Clarke, and R. E. Gorga, "Edge electrospinning for high throughput production of quality nanofibers," Nanotechnology, vol. 22, no. 34, Article ID 345301, 2011.

[5] R. Ramaseshan, S. Sundarrajan, R. Jose, and S. Ramakrishna, "Nanostructured ceramics by electrospinning," Journal of Applied Physics, vol. 102, no. 11, Article ID 111101, 2007.

[6] J. Watthanaarun, V. Pavarajarn, and P. Supaphol, “Titanium (IV) oxide nanofibers by combined sol-gel and electrospinning techniques: preliminary report on effects of preparation conditions and secondary metal dopant," Science and Technology of Advanced Materials, vol. 6, no. 3-4, pp. 240-245, 2005.

[7] K. Fujihara, A. Kumar, R. Jose, S. Ramakrishna, and S. Uchida, "Spray deposition of electrospun $\mathrm{TiO}_{2}$ nanorods for dyesensitized solar cell," Nanotechnology, vol. 18, no. 36, Article ID 365709, pp. 1-5, 2007.

[8] K. Nakata and A. Fujishima, " $\mathrm{TiO}_{2}$ photocatalysis: design and applications," Journal of Photochemistry and Photobiology C: Photochemistry Reviews, vol. 13, no. 3, pp. 169-189, 2012.
[9] T. Picatonotto, D. Vione, and M. Eugenia Carlotti, "Effect of some additives used in the cosmetic field on the photocatalytic activity of rutile," Journal of Dispersion Science and Technology, vol. 23, no. 6, pp. 845-852, 2002.

[10] A. R. Boccaccini, J. J. Blaker, V. Maquet, W. Chung, R. Jérôme, and S. N. Nazhat, "Poly(D,L-lactide) (PDLLA) foams with $\mathrm{TiO}_{2}$ nanoparticles and $\mathrm{PDLLA} / \mathrm{TiO}_{2}$-Bioglass foam composites for tissue engineering scaffolds," Journal of Materials Science, vol. 41, no. 13, pp. 3999-4008, 2006.

[11] Z. Ma, M. Kotaki, R. Inai, and S. Ramakrishna, "Potential of nanofiber matrix as tissue-engineering scaffolds," Tissue Engineering, vol. 11, no. 1-2, pp. 101-109, 2005.

[12] D. Reyes-Coronado, G. Rodríguez-Gattorno, M. E. EspinosaPesqueira, C. Cab, R. de Coss, and G. Oskam, "Phase-pure $\mathrm{TiO}_{2}$ nanoparticles: anatase, brookite and rutile," Nanotechnology, vol. 19, no. 14, Article ID 145605, 2008.

[13] M. Sangmanee and S. Maensiri, "Nanostructures and magnetic properties of cobalt ferrite $\left(\mathrm{CoFe}_{2} \mathrm{O}_{4}\right)$ fabricated by electrospinning," Applied Physics A, vol. 97, no. 1, pp. 167-177, 2009.

[14] S. Tungprapa, T. Puangparn, M. Weerasombut et al., "Electrospun cellulose acetate fibers: effect of solvent system on morphology and fiber diameter," Cellulose, vol. 14, no. 6, pp. 563-575, 2007.

[15] W. Nuansing, S. Ninmuang, W. Jarernboon, S. Maensiri, and S. Seraphin, "Structural characterization and morphology of electrospun $\mathrm{TiO}_{2}$ nanofibers," Materials Science and Engineering B, vol. 131, no. 1-3, pp. 147-155, 2006.

[16] P. Viswanathamurthi, N. Bhattarai, H. Y. Kim, and D. R. Lee, "Vanadium pentoxide nanofibers by electrospinning," Scripta Materialia, vol. 49, no. 6, pp. 577-581, 2003.

[17] S. Maensiri and W. Nuansing, "Thermoelectric oxide $\mathrm{NaCo}_{2} \mathrm{O}_{4}$ nanofibers fabricated by electrospinning," Materials Chemistry and Physics, vol. 99, no. 1, pp. 104-108, 2006.

[18] J.-A. Park, J. Moon, S.-J. Lee, S. H. Kim, T. Zyung, and H. Y. Chu, "Structural, electrical and gas sensing properties of eletrospun $\mathrm{TiO}_{2}$ nanofibers," Thin Solid Films, vol. 518, no. 22, pp. 66426645, 2010.

[19] H. S. Lee, C. S. Woo, B. K. Youn et al., "Bandgap modulation of $\mathrm{TiO}_{2}$ and its effect on the activity in photocatalytic oxidation of 2-isopropyl-6-methyl-4-pyrimidinol," Topics in Catalysis, vol. 35, no. 3-4, pp. 255-260, 2005.

[20] N. Xu, Z. Shi, Y. Fan, J. Dong, J. Shi, and M. Z.-C. Hu, "Effects of particle size of $\mathrm{TiO}_{2}$ on photocatalytic degradation of methylene blue in aqueous suspensions," Industrial and Engineering Chemistry Research, vol. 38, no. 2, pp. 373-379, 1999.

[21] S. Wiechers, P. Biehl, C. Luven et al., "Titanium dioxide particle size vs. sun protection performance," Cosmetics \& Toiletries, vol. 128, no. 5, pp. 2-6, 2013.

[22] C. Tekmen, A. Suslu, and U. Cocen, "Titania nanofibers prepared by electrospinning," Materials Letters, vol. 62, no. 29, pp. 4470-4472, 2008.

[23] I. Cacciotti, A. Bianco, G. Pezzotti, and G. Gusmano, "Synthesis, thermal behaviour and luminescence properties of rare earthdoped titania nanofibers," Chemical Engineering Journal, vol. 166, no. 2, pp. 751-764, 2011. 

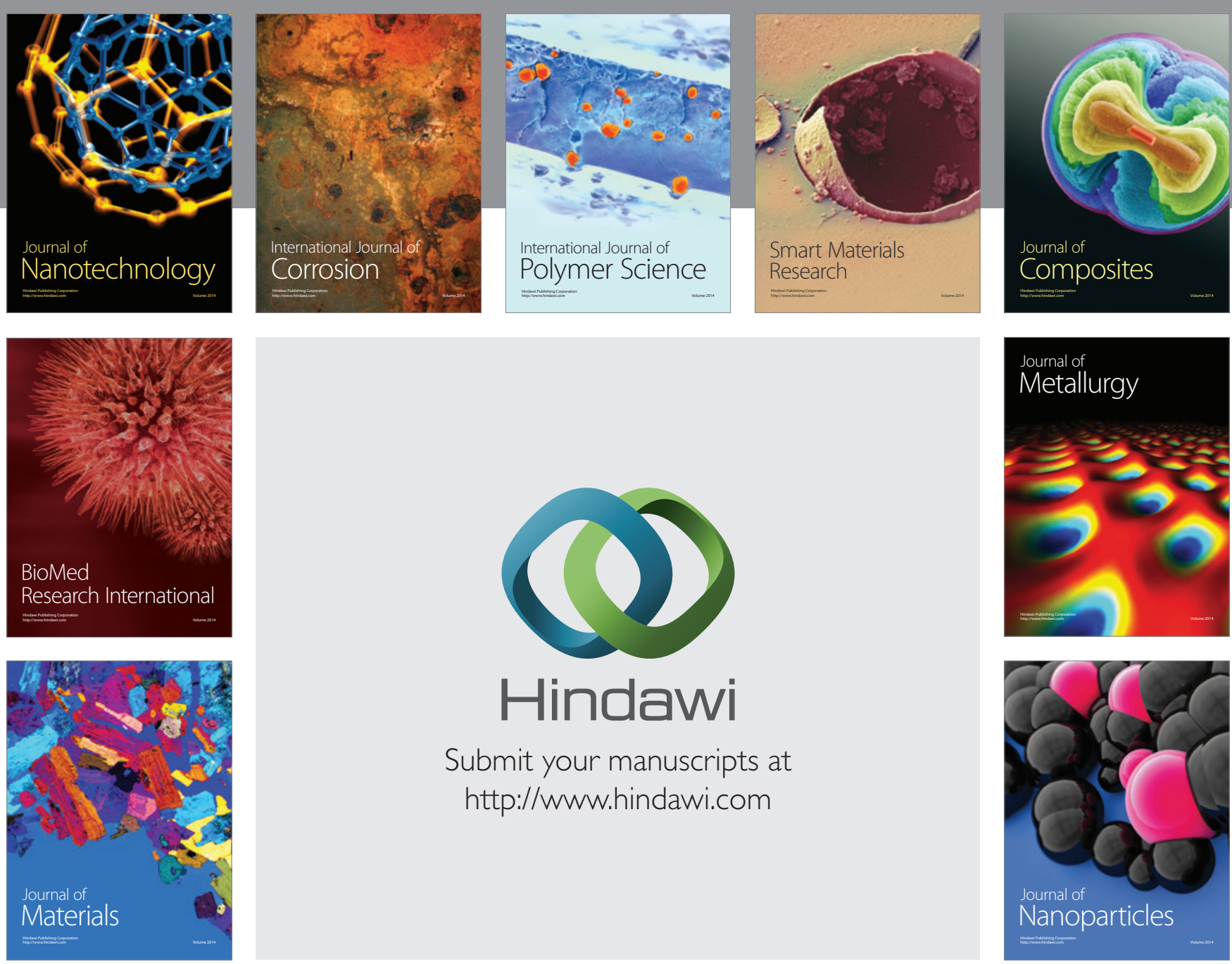

Submit your manuscripts at http://www.hindawi.com
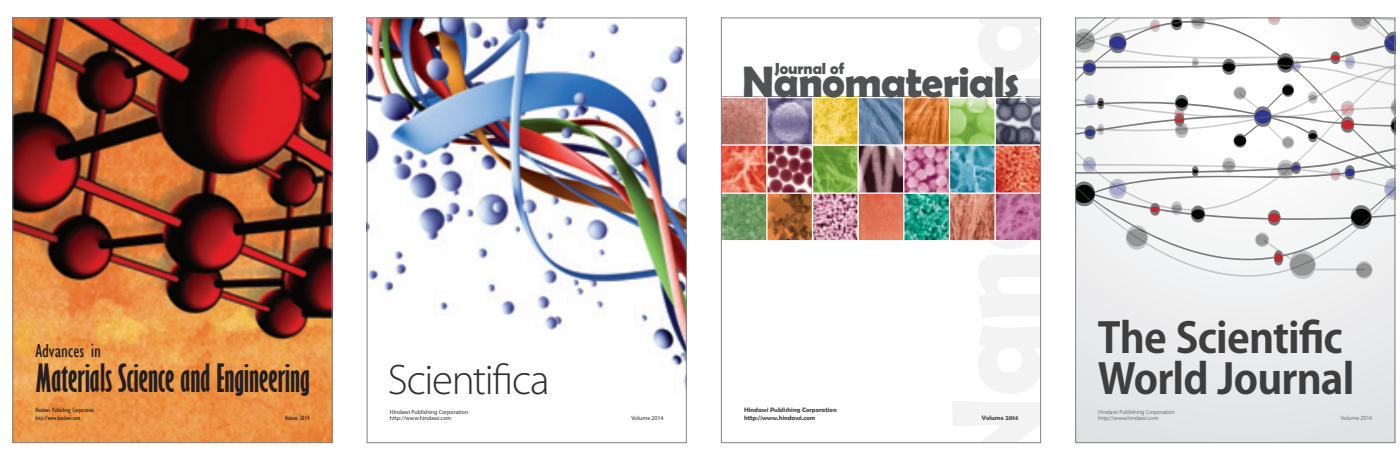

\section{The Scientific World Journal}
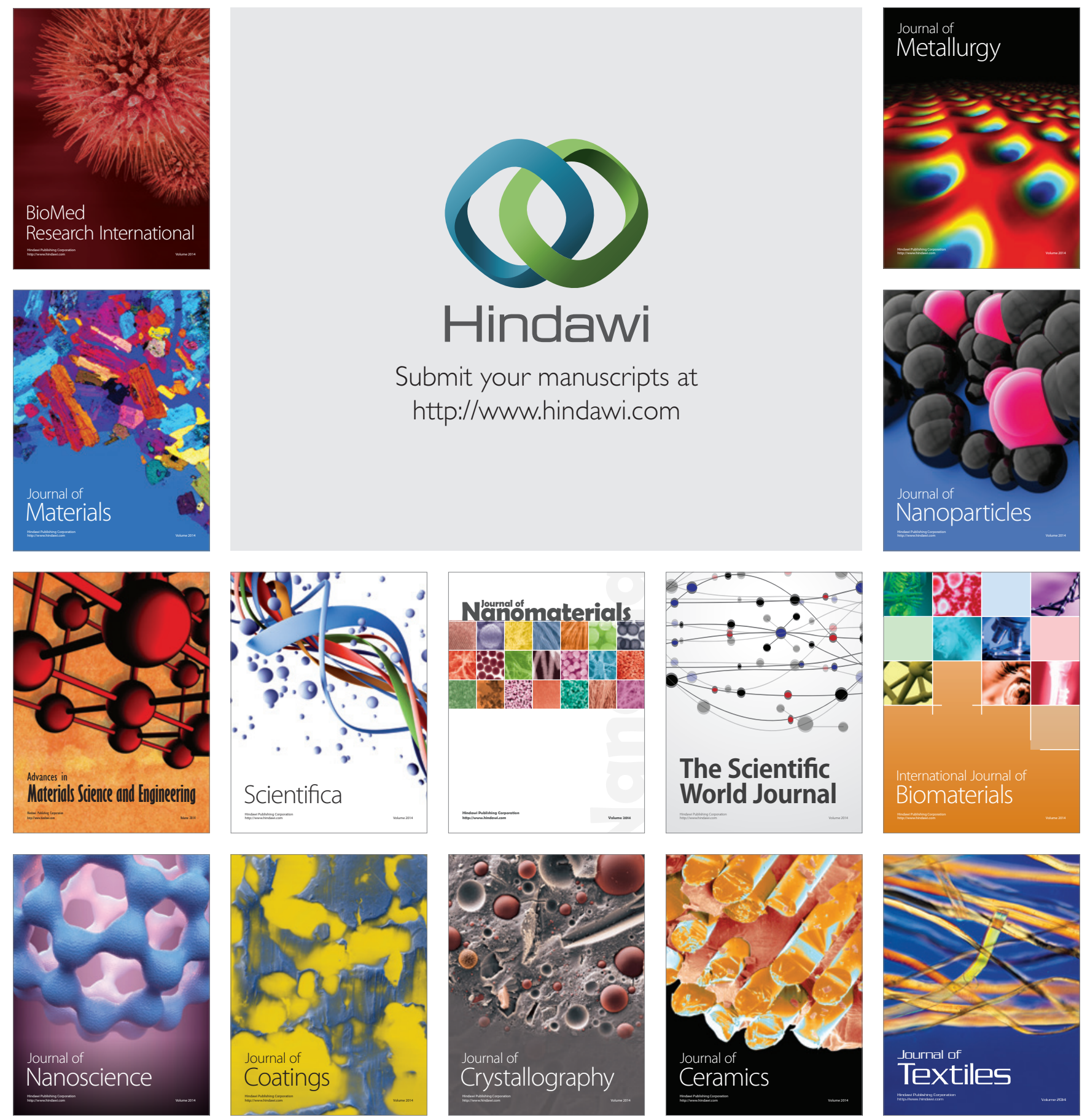